\title{
Oxidation Process of Adrenaline in Freshly Isolated Rat Cardiomyocytes: Formation of Adrenochrome, Quinoproteins, and GSH Adduct
}

\author{
Vera Marisa Costa $,{ }^{*},{ }^{\dagger}$ Renata Silva ${ }^{\dagger}$ Luísa Maria Ferreira, ${ }^{\dagger}$ Paula Sério Branco, ${ }^{\ddagger}$ \\ Félix Carvalho, ${ }^{\dagger}$ Maria Lourdes Bastos, ${ }^{\dagger}$ Rui Albuquerque Carvalho, ${ }^{\S}$ Márcia Carvalho, ${ }^{\dagger, I I}$ \\ and Fernando Remião*,, \\ REQUIMTE (Rede de Química e Tecnologia), Toxicology Department, Faculty of Pharmacy, University of \\ Porto, Porto, Portugal, REQUIMTE/CQFB (Centro de Química Fina e Biotecnologia), Chemistry Department, \\ Faculty of Science and Technology, University Nova de Lisboa, Monte da Caparica, Portugal, Neurosciences \\ Center of Coimbra, University of Coimbra, Coimbra, Portugal, and Faculty of Health Sciences, University
} Fernando Pessoa, Porto, Portugal

Received March 27, 2007

\begin{abstract}
High concentrations of circulating biogenic catecholamines often exist during the course of several cardiovascular disorders. Additionally, coronary dysfunctions are prominent and frequently related to the ischemic and reperfusion phenomenon (I/R) in the heart, which leads to the release of large amounts of catecholamines, namely adrenaline, and to a sustained generation of reactive oxygen species (ROS). Thus, this work aimed to study the toxicity of adrenaline either alone or in the presence of a system capable of generating ROS [xanthine with xanthine oxidase (X/XO)], in freshly isolated, calcium tolerant cardiomyocytes from adult rats. Studies were performed for $3 \mathrm{~h}$, and cardiomyocyte viability, ATP level, lipid peroxidation, protein carbonylation content, and glutathione status were evaluated, in addition to the formation of adrenaline's oxidation products and quinoproteins. Intracellular GSH levels were timedependently depleted with no GSSG formation when cardiomyocytes were exposed to adrenaline or to adrenaline with X/XO. Meanwhile, a time-dependent increase in the rate of formation of adrenochrome and quinoproteins was observed. Additionally, as a new outcome, 5-(glutathion- $S$-yl)adrenaline, an adrenaline adduct of glutathione, was identified and quantified. Noteworthy is the fact that the exposure to adrenaline alone promotes a higher rate of formation of quinoproteins and glutathione adduct, while adrenochrome formation is favored where ROS production is stimulated. This study shows that the redox status of the surrounding environment greatly influences adrenaline's oxidation pathway, which may trigger cellular changes responsible for cardiotoxicity.
\end{abstract}

\section{Introduction}

An estimated one-third of total global deaths result from the various forms of cardiovascular diseases, ischemic heart disease being the main cause (1). Although they were considered diseases of developed countries, since half of all deaths in the United States are related to cardiovascular diseases (2), a new reality is emerging, and it is estimated that by 2010 cardiovascular diseases will be the leading cause of death in developing countries (1).

When a stressful stimulus occurs, adrenaline and noradrenaline are released, throughout the nervous system and adrenal medulla (3). The cardiac sympathetic nerves are preferentially stimulated in severe heart failure, which includes a 50 -fold increase in the rate of spillover of noradrenaline, but also a large release of the sympathetic co-transmitters, adrenaline and neuropeptide Y (4). During an ischemic phenomenon, the

\footnotetext{
* To whom correspondence should be addressed: REQUIMTE, Departamento de Toxicologia, Faculdade de Farmácia, Universidade do Porto, Rua Aníbal Cunha, 164 4099-030 Porto, Portugal. Phone: 00351-222078979. Fax: 00351-222003977. V.M.C.: e-mail, veramcosta@ff.up.pt. F.R.: e-mail, remiao@ff.up.pt.

University of Porto.

* University Nova de Lisboa.

${ }^{\S}$ University of Coimbra.

"University Fernando Pessoa.
}

concentrations of noradrenaline and adrenaline rise progressively in the interstitial myocardial fluid $(3,5)$. Elevated concentrations of circulating catecholamines are also found in arrhythmias, myocardial necrosis $(3,5)$, heart failure (4), exercise (6), pheochromocytoma (7), hypoglycemia, hemorrhagic hypotension, circulatory collapse, and distress (8). Additionally, catecholamines have been widely used for decades in cardiovascular therapy (adrenaline has been used for cardiopulmonary resuscitation for more than 100 years) $(9,10)$.

Ischemic and reperfusion phenomenon (I/R), a coronary dysfunction, is associated with oxidative stress. In fact, in postischemic myocardium, $\operatorname{ROS}^{1}$ are formed at an accelerated rate (11-13), playing a major role in pathogenesis. Cardiac myocytes, endothelial cells, and infiltrating neutrophils contribute to ROS production (2). High levels of ROS are also found in exercise (14), and in many pathological conditions, such as inflammation $(15,16)$, neurodegeneration (17), and aging (18).

Although the toxicity of catecholamines is mainly related to the stimulation of adrenoreceptors, there is a growing body of evidence which shows that their oxidation is also responsible

\footnotetext{
${ }^{1}$ Abbreviations: ADR, adrenaline; $\mathrm{X} / \mathrm{XO}$, xanthine and xanthine oxidase; $\mathrm{GSH}$, reduced glutathione; GSSG, oxidized glutathione; GSHt, total glutathione; ROS, reactive oxygen species; I/R, ischemia and reperfusion; LDH, lactate dehydrogenase; GR, glutathione redutase; GPx, glutathione peroxidase; GST, glutathione $S$-transferase.
} 
for cardiotoxicity $(13,19,20)$. The oxidation of catecholamines at physiological $\mathrm{pH}$ seems to occur very slowly; however, it increases considerably by enzymatic or metal catalysis $(19,21,22)$ or in the presence of superoxide anion $\left(\mathrm{O}_{2}{ }^{-}\right)$(23). Therefore, oxidation of adrenaline in vivo is possible in some circumstances, as in I/R. In accordance, products of this oxidation have been described in the heart, skeletal muscle, liver, and blood (20). The oxidative pathway of catecholamines generates various highly reactive intermediaries, like $o$-quinones, aminochromes, aminolutins, and melanins (19), which can react with external nucleophilic groups, especially $\mathrm{SH}$ groups, present in cysteine, glutathione, and proteins (24-26) or $\mathrm{OH}$ and $\mathrm{NH}_{2}$ groups also in proteins (27). For instance, adrenochrome is capable of inhibiting the activity of several enzymes $(19,28)$, thus greatly modifying cellular metabolism (20). The interaction of adrenochrome with $\mathrm{SH}$ groups and the induced depletion of oxygen, ascorbate, and glutathione may cause noxious effects toward the cellular function and defenses (28).

In addition, the conjugation of oxidation products of catecholamines with GSH is no longer considered a simple detoxification route. In fact, these adducts have been reported to induce toxicity. Actually, they seem to be involved in the pathogenesis of Parkinson's disease $(24,29)$ and in the toxicity of the illicit drugs MDMA (3,4-methylenedioxymethamphetamine) $(30,31)$ or methamphetamine $(26)$.

Our work aimed to provide new insight into the toxicity induced by adrenaline, ROS, and their concomitant effects in freshly isolated calcium tolerant cardiomyocytes obtained from adult rat, a suitable in vitro model for evaluating the mechanisms involved in the toxicity toward these muscle cells $(32,33)$. The $\mathrm{X} / \mathrm{XO}$ system was used to mimic an oxidative stress environment, which, as stated above, is present in several pathologies, some of those with concomitant release of large quantities of catecholamines.

The studies on tolerant calcium cardiomyocytes were performed for a maximum period of $3 \mathrm{~h}$, and cellular viability, oxidation products of adrenaline, glutathione status, quinoproteins, and glutathione adduct were evaluated during the time course of the experiments to determine the mechanistic pathway of adrenaline's oxidation when alone and compare it with that in the presence of ROS.

\section{Materials and Methods}

Animals. Adult male Sprague-Dawley rats (Charles River Laboratories, Barcelona, Spain) weighing 250-350 g were used. The animals were housed in cages with a temperature- and humidity-controlled environment. Food and water were provided ad libitum, and animals were subjected to a $12 \mathrm{~h}$ light-dark cycle. Animal experiments were licensed by the Portuguese General Directory of Veterinary Medicine. Housing and experimental treatment of the animals were in accordance with the Guide for the Care and Use of Laboratory Animals from the Institute for Laboratory Animal Research (ILAR 1996). The experiments complied with current Portuguese laws.

Chemicals. All reagents used in this study were of analytical grade. Collagenase type II was obtained from Worthington (Lakewood, NJ). Collagenase (type IA), bovine serum albumin (fraction V), $N$-(2-hydroxyethyl)piperazine- $N$-(2-ethanesulfonic acid) (HEPES), reduced glutathione (GSH), oxidized glutathione (GSSG), glutathione redutase (GR, EC 1.6.4.2), 2-vinylpyridine, reduced $\beta$-nicotinamide adenine dinucleotide phosphate $(\beta$-NADPH), reduced $\beta$-nicotinamide adenine dinucleotide ( $\beta$-NADH), 5,5-dithiobis(2-nitrobenzoic acid) (DTNB), adenosine triphosphate (ATP), pyruvic acid, phenylmethanesulfonyl (PMSF), nitroblue tetrazolium (NBT), 1-chloro-2,4-dinitrobenzene, 1-octanesulfonic acid, mushroom tyrosinase, $\gamma$-glutamyltranspeptidase $(\gamma$-GT, EC 2.3.2.2), luciferase, luciferin, and all reagents for enzymatic determinations were obtained from Sigma-Aldrich (St. Louis, MO). Citric acid, methanol (gradient grade), perchloric acid, and all other chemicals were purchased from Merck (Darmstadt, Germany).

5-(Glutathion-S-yl)adrenaline Synthesis and RMN Analysis. The synthesis of the adduct of adrenaline with GSH followed previously published methods (34) for other catecholamine-GSH adducts.

To a solution of $(-)$-adrenaline $\left(0.010 \mathrm{~g}, 5.46 \times 10^{-5} \mathrm{~mol}\right)$ in sodium phosphate buffer $(20 \mathrm{~mL}, \mathrm{pH} 7.4,50 \mathrm{mM})$ at $25^{\circ} \mathrm{C}$ was added mushroom tyrosinase (4000 units, 200 units $/ \mathrm{mL}$ of buffer). The solution became red, indicating the formation of $o$-quinone. GSH $\left(0.0335 \mathrm{~g}, 1.09 \times 10^{-4} \mathrm{~mol}\right)$ was added, and the red-colored solution changed with time to yellow $(19 \mathrm{~h})$. At the terminus of the reaction, $1 \mathrm{~mL}$ of $88 \%$ formic acid was added, and the solution was carefully concentrated by rotary evaporation without heating. The purification of the product was performed by reverse-phase RP-18 modified silica column chromatography (Merck KGaA) first with water $(150 \mathrm{~mL})$ and then $10 \times 10 \mathrm{~mL}$ of $10 \%$ methanol followed by $10 \times 10 \mathrm{~mL}$ of $20 \%$ methanol. Each fraction was checked for the presence of adduct using a UV-vis detector. Fractions containing maxima at 260 and $292 \mathrm{~nm}$ were separated and carefully evaporated to dryness. Due to the fact that glutathione was difficult to separate from the adrenaline adduct, further purification by HPLC was necessary using a LiChrospher 100 RP18 column (Merck KGaA), with two mobile-phase solvents. Solvent A was prepared by adding concentrated trifluoroacetic acid (TFA) to deionized water until the $\mathrm{pH}$ reached 2.5. Solvent $\mathrm{B}$ was prepared by adding TFA to a 1:1 mixture of acetonitrile $(\mathrm{MeCN})$ and deionized water until the $\mathrm{pH}$ reached 2.6. The mobile phase was made of solvents $\mathrm{A}$ and $\mathrm{B}$, and the following gradient was used: 100 to $85 \%$ solvent A from 0 to $25 \mathrm{~min}, 85$ to $65 \%$ solvent A from 25 to $32 \mathrm{~min}, 65$ to $0 \%$ solvent A from 32 to $37 \mathrm{~min}$, and $100 \%$ solvent A from 37 to $42 \mathrm{~min}$. The compounds eluted within 10 min. The peaks were monitored at $290 \mathrm{~nm}$. 5-(Glutathion- $S$ yl)adrenaline $(0.006 \mathrm{~g})$ was obtained as an oil in $22.5 \%$ yield: ${ }^{1} \mathrm{H}$ NMR $\left(\mathrm{D}_{2} \mathrm{O}\right) \delta 2.07(2 \mathrm{H}, \mathrm{m}, \mathrm{Glu}-\beta), 2.41(2 \mathrm{H}, \mathrm{m}, \mathrm{Glu}-\gamma), 2.67$ $\left(3 \mathrm{H}, \mathrm{s}, \mathrm{N}-\mathrm{CH}_{3}\right), 3.14\left(3 \mathrm{H}, \mathrm{m}, \mathrm{Cys}-\beta, \mathrm{CH}_{2}\right), 3.28(1 \mathrm{H}, \mathrm{m}, \mathrm{Cys}-\beta)$, $3.75(1 \mathrm{H}, \mathrm{s}$, Gly- $\alpha), 3.91(2 \mathrm{H}, \mathrm{m}, \mathrm{Glu}-\alpha), 6.83\left(1 \mathrm{H}, \mathrm{s}, \mathrm{ArH}_{2^{\prime} / 6^{\prime}}\right)$, $6.93\left(1 \mathrm{H}, \mathrm{s}, \mathrm{ArH}_{2^{\prime} / 6^{\prime}}\right)$; MALDI-TOF (sinapinic acid) $\mathrm{m} / \mathrm{z} 489.5$ $[\mathrm{MH}]^{+}, 511.5[\mathrm{M}+\mathrm{Na}]^{+}$.

Calcium Tolerant Cardiomyocytes Isolated from Adult Rat. Calcium tolerant cardiomyocytes were isolated by Langendorff retro perfusion of adult rat heart as previously described $(35,36)$, with some modifications. The procedure was based on (i) successive treatments with calcium free medium and (ii) digestion with collagenases (collagenase type II and collagenase type IA in a 200 $\mu \mathrm{M}$ calcium-modified Krebs-Henseleit buffer solution), followed by (iii) gentle mechanical disaggregation. Calcium tolerant cardiomyocytes were obtained by gradual re-introduction of calcium until a final concentration of $1 \mathrm{mM}$. All steps were performed in modified Krebs-Henseleit buffer containing $102 \mathrm{mM} \mathrm{NaCl}, 4 \mathrm{mM} \mathrm{KCl}, 1$ $\mathrm{mM} \mathrm{MgSO}{ }_{4}, 10 \mathrm{mM}$ glucose, $5.5 \mathrm{mM} \mathrm{NaHCO}_{3}, 0.9 \mathrm{mM} \mathrm{KH}_{2} \mathrm{PO}_{4}$, and $22 \mathrm{mM}$ HEPES ( $\mathrm{pH}$ adjusted to 7.2-7.4) saturated with a gaseous stream of carbogen $\left(95 \% \mathrm{O}_{2}\right.$ and $\left.5 \% \mathrm{CO}_{2}\right)$. At the beginning of the experiments, cell viability was always greater than $60 \%$, evaluated by the lactate dehydrogenase (LDH) leakage assay and by microscopic evaluation of cardiomyocyte morphology. The obtained viability is in accordance with previous reports for calcium tolerant cardiomyocytes (37-39). This viability was obtained after a 5 min preincubation at $37{ }^{\circ} \mathrm{C}$ to guarantee the correspondence between values obtained via manual counting and a LDH leakage assay. Incubations were performed in a water bath at $37^{\circ} \mathrm{C}$, using a density of $2.5 \times 10^{5}$ viable cells $/ \mathrm{mL}$ in the modified KrebsHenseleit buffer supplemented with $1 \mathrm{mM} \mathrm{CaCl}_{2}(\mathrm{pH} \mathrm{7.4)}$ and saturated with an air stream of carbogen, every hour. After a preincubation for $30 \mathrm{~min}$ at $37^{\circ} \mathrm{C}$, the compounds were tested using the following protocol: (i) control cells, with no treatment; (ii) cells incubated with adrenaline (ADR) alone; (iii) cells incubated with $\mathrm{ADR}$ and $\mathrm{X} / \mathrm{XO}$; and (iv) cells exposed to the $\mathrm{X} / \mathrm{XO}$ system alone. 
The final concentrations were as follows: $0.5 \mathrm{mM}$ ADR (unless otherwise mentioned), $0.1 \mathrm{mM}$ xanthine, and $0.01 \mathrm{unit} / \mathrm{mL}$ xanthine oxidase.

Sample Treatment. At incubation times of $0,1,2$, and $3 \mathrm{~h}$, determinations were performed directly using the cardiomyocyte suspension or after centrifugation at $18 \mathrm{~g}$ for $2 \mathrm{~min}$, for separation of supernatant and pellet, as previously described (38). The supernatant is termed the incubation medium. The pellet was washed two times with $1 \mathrm{~mL}$ of modified Krebs-Henseleit buffer supplemented with $1 \mathrm{mM} \mathrm{CaCl}_{2}$, centrifuged at $18 g$ for $2 \mathrm{~min}$, and finally treated according to the chemical and biochemical determinations for cardiomyocytes. Washing solutions obtained after centrifugation were rejected.

Cell Viability Assays. 1. Lactate Dehydrogenase Leakage Assay. The LDH leakage assay was directly performed in the cardiomyocyte suspensions to evaluate the level of cell injury at time zero (immediately after addition of the compounds) and after incubation for $3 \mathrm{~h}$ in all treatments, as previously described (38).

2. Morphology. The percentage of rod-shaped cells was determined using a Neubauer chamber, as previously described (40). Cells with a length/width ratio of $>4$ were considered rod-shaped cells.

Measurement of Total GSH (GSHt), GSH, and GSSG Levels. The cardiomyocyte and incubation medium levels of GSH and GSSG were measured by the DTNB-GSSG redutase recycling assay, as previously described (41). Both the incubation medium and cardiomyocytes were acidified to a final concentration of $5 \%$ $\mathrm{HClO}_{4}$ and centrifuged, and the supernatant obtained was used for the measurements.

Determination of GPx, GR, and GST Intracellular Activities. For the determination of glutathione peroxidase (GPx), glutathione redutase (GR), and glutathione $S$-transferase (GST) activities, aliquots of the cell suspension were sonicated for $12 \mathrm{~s}$ at intensity 4 in a VibraCell sonicater (Sonics \& Materials Inc., Danbury, CT) and then centrifuged at $16000 \mathrm{~g}$ for $10 \mathrm{~min}$. The GPx, GR, and GST activities were determined in the supernatant that was obtained, as previously described (42). Briefly, GR activity was determined by following NADPH oxidation at $340 \mathrm{~nm}$ during the reduction of GSSG to GSH. Selenium-dependent GPx activity was determined by following NADPH oxidation at $340 \mathrm{~nm}$ after reduction of GSSG by GR. Finally, GST activity was determined by following the formation of the GSH conjugate with 1-chloro2,4-dinitrobenzene, which was monitored at $340 \mathrm{~nm}$. All measurements were performed in triplicate in a 96-well plate reader.

Measurement of Cellular and Extracellular ATP Levels. The incubation medium and cardiomyocytes were acidified to a final concentration of $5 \% \mathrm{HClO}_{4}$ and centrifuged, and the supernatant obtained was used for the measurements. The level of ATP was measured by the bioluminescence test based on the work of De Luca et al. (43).

Assessment of Protein Carbonylation. Protein carbonyl groups were quantified in cardiomyocytes, as described by Levine et al. (44), by reaction with 2,4-dinitrophenylhydrazine (DNPH).

Protein Determination. The protein levels were determined as previously described by Lowry (45). Protein content for quinoproteins was determined by the method described by Bradford (46).

Assessment of Lipid Peroxidation. The extent of lipid peroxidation in suspension cells was measured by the assay for thiobarbituric acid reactive substances (TBARS) at $535 \mathrm{~nm}$, as previously described (42).

Assessment of Protein-Bound Quinones (Quinoproteins). For the assessment of protein-bound quinones in cardiomyocytes, the NBT/glycinate colorimetric assay was performed, which is based on the method described by Paz et al. (47), with a few adaptations. The cardiomyocytes were lysed in $200 \mu \mathrm{L}$ of ice-cold RIPA buffer, supplemented with $5 \mathrm{mM}$ PMSF. The samples were sonicated at intensity 4 in the VibraCell sonicater for $3 \mathrm{~s}$, and the whole protein content was quantified by the Bradford method (46), using BSA as a protein standard. Twenty-five micrograms of the lysates in RIPA buffer was added to $240 \mu \mathrm{L}$ of a $2 \mathrm{M}$ potassium glycinate ( $\mathrm{pH} 10)$ solution. To this last solution was added $500 \mu \mathrm{L}$ of NBT reagent [0.24 mM NBT in $2 \mathrm{M}$ potassium glycinate ( $\mathrm{pH} 10)]$. The reaction was performed for $3 \mathrm{~h}$ at room temperature in the dark, after which the absorbance was read at $530 \mathrm{~nm}$ in a 96-well plate reader.

HPLC-DAD/EC Analysis. Adrenochrome and adrenaline in the incubation medium were quantified by HPLC (Waters model 2690) with a photodiode array detector (DAD), at $279 \mathrm{~nm}$ (for catecholamine) and $300 \mathrm{~nm}$ (for aminochrome), as previously described (40).

The quantification of adrenaline levels in the cardiomyocytes and of adrenaline-GSH adduct was performed with the same HPLC instrument equipped with an electrochemical detector (EC), as previously described (48).

The incubation medium and cardiomyocytes, these last after being washed two times as described in Sample Treatment, were acidified to a final concentration of $5 \% \mathrm{HClO}_{4}$ and centrifuged, and the supernatant obtained was used for the measurements. After sampling, the acidic samples were supplemented with ascorbic acid ( $5 \mathrm{mM}$, final concentration), to avoid further formation of the GSH adduct. Storage was at $-80{ }^{\circ} \mathrm{C}$, with HPLC-EC analysis being performed within $24 \mathrm{~h}$ of treatment. Previous studies were performed to guarantee the stability of the adduct and to avoid chemical formation of the adduct during storage.

Quantitative measurements of adrenaline content (in the cells), as well as of the GSH-adrenaline adduct (in the cells and incubation medium), were carried out by interpolation of standard curves obtained by injection of standard solutions of adrenaline and the GSH-adrenaline adduct, by a previously validated method (48).

To confirm the presence of the GSH adduct, cardiomyocytes and incubation medium aliquots were spiked with 5-(glutathion- $S$ yl)adrenaline standard. Moreover, to strengthen identification of the GSH conjugate, aliquots were treated with $\gamma$-glutamyltranspeptidase $(\gamma$-GT), according to the method of Carvalho et al. (41), with minor modifications. This procedure allowed the identification of GSH adducts, since $\gamma$-GT cleaves the $\gamma$-glutamyl bond of GSH (49). The cardiomyocytes were sonicated (12 s at intensity 4 in the device described above) and then treated with $\gamma$-GT (final concentration of $4 \mathrm{IU}$ in Krebs-Henseleit buffer) for $5 \mathrm{~min}$ before protein precipitation with $5 \% \mathrm{HClO}_{4}$ (final concentration). Incubation medium samples were placed in contact with $\gamma$-GT (final concentration of $4 \mathrm{IU}$ in Krebs-Henseleit buffer) for $5 \mathrm{~min}$ at room temperature before protein precipitation with $5 \% \mathrm{HClO}_{4}$ (final concentration). Both samples were then centrifuged for $10 \mathrm{~min}$ at $16000 \mathrm{~g}$, and the supernatant obtained was injected into the HPLCEC system.

Statistical Analysis. Results are given as means \pm the standard deviation (SD) from six independent experiments with suspensions of cardiomyocytes proceeding from six different rats. Nonparametric tests were used. Statistical comparisons between groups were performed with a Kruskal-Wallis test (one-way ANOVA on Ranks) followed by the Student-Newman-Keuls post hoc test, once a significant $p$ had been obtained.

When only two treatment groups were compared, the MannWhitney Rank Sum test was used. Details of the statistical analysis are described in each figure legend. Significance was accepted at $p$ values of $<0.05$.

\section{Results}

Changes in the Concentration of Adrenaline and Adrenochrome. The measurement of adrenaline and adrenochrome levels was performed in cardiomyocytes and incubation medium of cell suspensions incubated with ADR or with ADR and $\mathrm{X} / \mathrm{XO}$. In control or X/XO cells, no adrenaline or adrenochrome was detected.

In cardiomyocytes after incubation for $3 \mathrm{~h}$, a significantly higher concentration of adrenaline was found in the ADR group $\left(12 \pm 1 \mathrm{nmol}\right.$ of ADR/2.5 $\times 10^{5}$ cardiomyocytes $)$ when compared with the group with ADR and $\mathrm{X} / \mathrm{XO}(8 \pm 1 \mathrm{nmol}$ of $\mathrm{ADR} / 2.5 \times 10^{5}$ cardiomyocytes). 

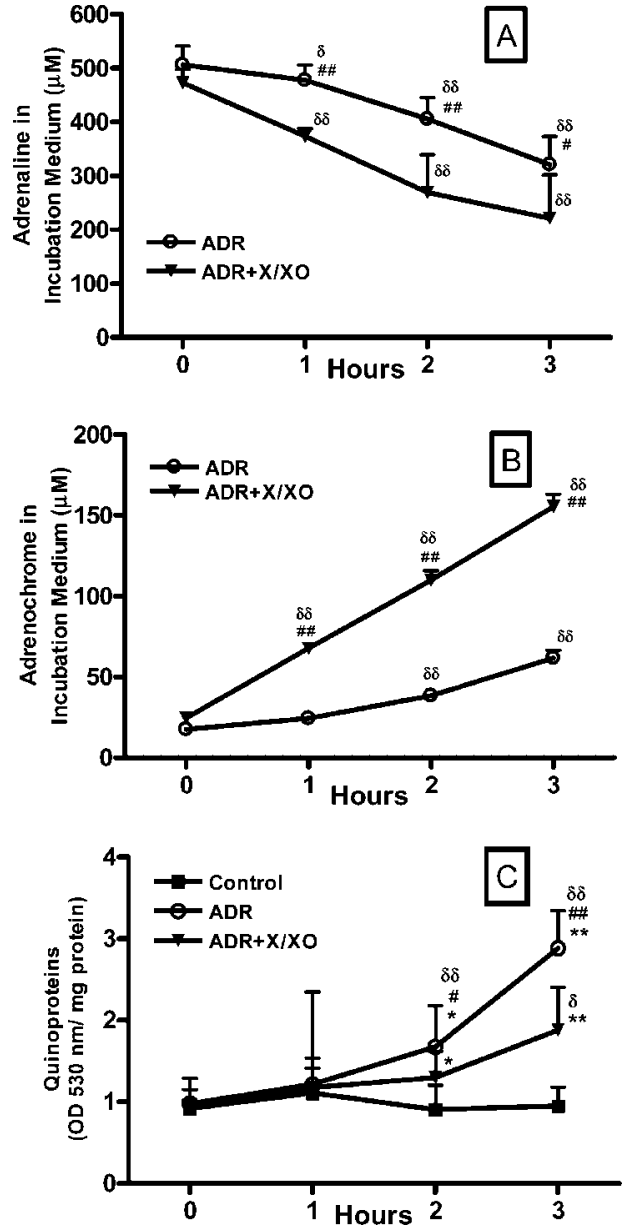

Figure 1. Levels of adrenaline (A) and adrenochrome (B) in incubation medium and of quinoproteins in cardiomyocytes $(\mathrm{C})$ of cell suspensions incubated with $0.5 \mathrm{mM}$ ADR and $0.5 \mathrm{mM}$ ADR with X/XO. Results are presented as means \pm SD from six different experiments. Statistical comparisons were made using Kruskal-Wallis test followed by the Student-Newman-Keuls post hoc test: $* p<0.05$ and $* * p<0.01$ vs control; ${ }^{\#} p<0.05$ and ${ }^{\# \#} p<0.01$ for ADR vs ADR and X/XO groups; and ${ }^{\delta} p<0.05$ and ${ }^{\delta} \delta_{p}<0.01$ vs time zero.

In the incubation medium, adrenaline was quantified each hour during the $3 \mathrm{~h}$ incubation. The concentration of adrenaline decreased rapidly from its initial value of $0.5 \mathrm{mM}$ in both treatments, although more rapidly in suspensions exposed to ADR and X/XO (Figure 1A). The difference between treatments was statistically significant as early as $1 \mathrm{~h}$. After incubation for $3 \mathrm{~h}$, the concentration of adrenaline was $321 \pm 52$ and $222 \pm$ $80 \mu \mathrm{M}$ in suspensions with $\mathrm{ADR}$ and with $\mathrm{ADR}$ and $\mathrm{X} / \mathrm{XO}$, respectively.

In the incubation medium, the decrease in adrenaline levels was accompanied by a time-dependent increase in the adrenochrome levels. This result was more evident in the group with $\mathrm{ADR}$ and $\mathrm{X} / \mathrm{XO}$, where values of adrenochrome reached 155 $\mu \mathrm{M}$, at $3 \mathrm{~h}$ (Figure $1 \mathrm{~B}$ ).

The adrenochrome peak was not detected in the cardiomyocytes in ADR group or ADR and X/XO group.

Adrenaline Oxidation Products Bind to Intracellular Proteins. The protein-bound quinone products (quinoproteins) present in cardiomyocytes were evaluated hourly, for all the treatments (Figure 1C). The measurements showed no significant differences between control cells and the X/XO group, at all time points (data not shown). Moreover, in the presence of ADR and ADR with $\mathrm{X} / \mathrm{XO}$, quinoprotein levels increased steadily in a time-dependent manner (Figure 1C). Quinoprotein levels in
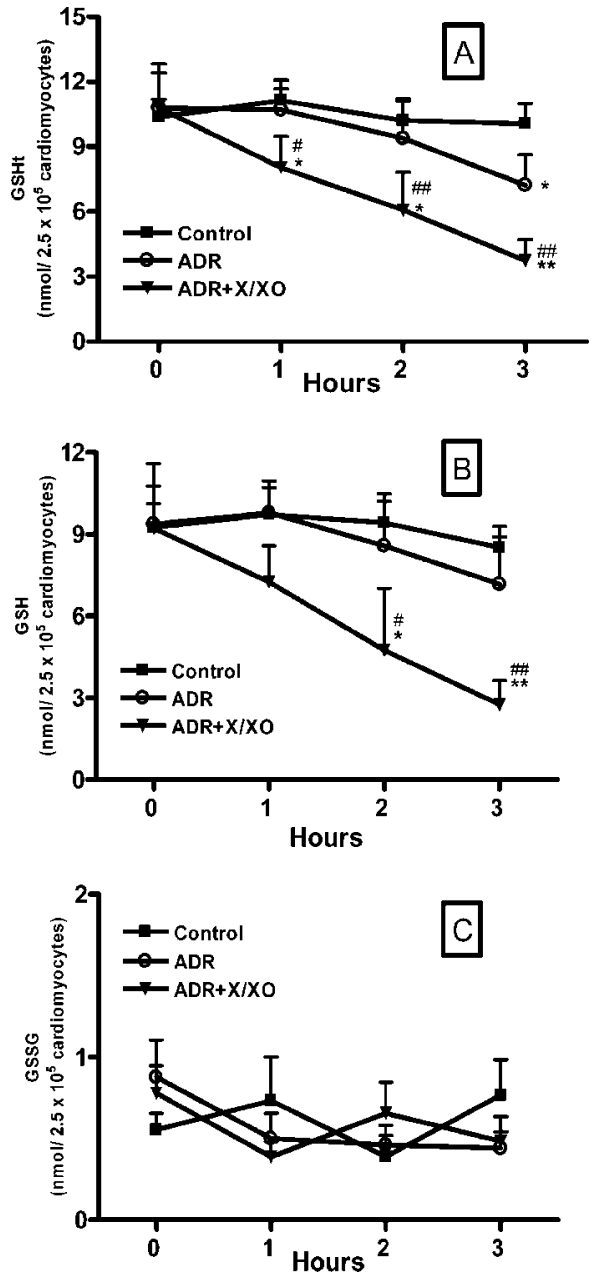

Figure 2. Intracellular glutathione levels [total (A), reduced (B), and oxidized (C)] in calcium tolerant rat cardiomyocytes: control, $0.5 \mathrm{mM}$ $\mathrm{ADR}$, and $0.5 \mathrm{mM}$ ADR with $\mathrm{X} / \mathrm{XO}$ for $3 \mathrm{~h}$. No statistical differences were found for the $\mathrm{X} / \mathrm{XO}$ system as an isolated treatment, when compared with control (data not shown). Results are presented as means \pm SD from six different experiments. Statistical comparisons were made using Kruskal-Wallis test, followed by the Student-Newman-Keuls post hoc test: $* p<0.05$ and $* * p<0.01$ vs control; and ${ }^{*} p<0.05$ and $\#^{\#} p<0.01$ for ADR vs ADR and X/XO groups.

the ADR cells at 2 and $3 \mathrm{~h}$ were 2 and 3 times higher, respectively, than in control. In the cells with ADR and $\mathrm{X} / \mathrm{XO}$, at $3 \mathrm{~h}$, the quinoprotein content was double control levels.

Alteration in Glutathione Status. In Figure 2, the levels of GSHt (Figure 2A), GSH (Figure 2B), and GSSG (Figure 2C) in cardiomyocytes, during the time course of a $3 \mathrm{~h}$ incubation in control, ADR, and ADR and X/XO cells, can be observed. There were no significant differences between the X/XO group and control (data not shown). However, the exposure to ADR caused a decrease in GSHt levels (Figure 2A), when compared to control. Additionally, the group with ADR and X/XO showed a more prominent decline in the content of both GSHt (Figure 2A) and GSH (Figure 2B). The differences between ADR and ADR with $\mathrm{X} / \mathrm{XO}$ became significant as early as $1 \mathrm{~h}$ for GSHt (Figure 2A) and $2 \mathrm{~h}$ for GSH (Figure 2B). It is worth mentioning that the levels of GSSG in cardiomyocytes did not suffer any alteration (Figure 2C) at any time point or group that was analyzed.

In addition, in the incubation medium, the levels of GSH and GSSG measured for all treatments showed no significant differences among them (data not shown).

Lower concentrations of ADR $(0.25$ and $0.1 \mathrm{mM})$ were also tested to determine variations of GSH and GSSG levels. No 

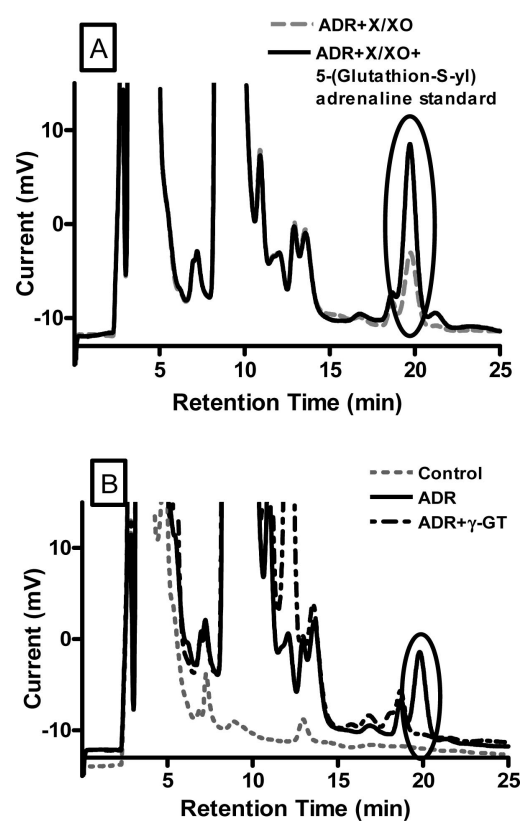

Figure 3. HPLC-EC chromatograms showing the peak corresponding to the 5-(glutathion- $S$-yl)adrenaline formed within the cells incubated with $0.5 \mathrm{mM} \mathrm{ADR}$ and $\mathrm{X} / \mathrm{XO}$ for $3 \mathrm{~h}(\mathrm{~A})$. The sample was injected with and without addition of the 5-(glutathion-S-yl)adrenaline standard (A), showing that the peaks have the same retention time. The peaks were obtained from cells incubated with $0.5 \mathrm{mM}$ ADR (B) before and after treatment with $\gamma$-GT for $3 \mathrm{~h}$. Treatment in control or in X/XO groups with $\gamma$-GT showed no interfering peaks (data not shown).

differences were registered among the groups when compared to control groups (data not shown), at a maximum incubation of $3 \mathrm{~h}$.

The sampling homogeneity was confirmed by protein levels, which remained fairly constant at all experimental times in each assay (data not shown).

Adrenaline Conjugated with Glutathione: Formation of 5-(Glutathion-S-yl)adrenaline. The depletion of GSHt and GSH with no GSSG formation may be explained by the conjugation between GSH and oxidation products of adrenaline. Thus, cardiomyocytes and incubation medium samples were collected and analyzed by HPLC-EC for GSH-adrenaline adduct detection, by a previously described method (48).

The 5-(glutathion- $S$-yl)adrenaline adduct was found in cardiomyocytes and in the incubation medium in ADR group and in $\mathrm{ADR}$ and $\mathrm{X} / \mathrm{XO}$ group. The chromatographic peak was confirmed as being 5-(glutathion- $S$-yl)adrenaline after co-elution with a 5-(glutathion- $S$-yl)adrenaline standard. The sample was also injected with and without addition of the 5-(glutathion- $S$ yl)adrenaline standard, showing that the peaks have the same retention time (Figure 3A). Additionally, the chromatographic peak of this adduct completely disappeared when samples (cardiomyocytes and incubation medium) were treated with $\gamma$-GT, which can be observed in Figure 3B. Treatment with $\gamma$-GT of the control or X/XO group showed no interfering peaks, either in the incubation medium or in cardiomyocytes (data not shown).

The levels of 5-(glutathion-S-yl)adrenaline were evaluated, and a higher level of formation of the GSH adduct was observed in cells incubated for $3 \mathrm{~h}$ with ADR [378 $\pm 48 \mathrm{pmol}$ of 5-(glutathion- $S$-yl)adrenaline/2.5 $\times 10^{5}$ cardiomyocytes] when compared with ADR and X/XO [115 \pm 32 pmol of 5-(glutathion- $S$-yl)adrenaline/2.5 $\times 10^{5}$ cardiomyocytes] (Figure 4), which represents an increase of more than 3 -fold in the first group compared to the latter.

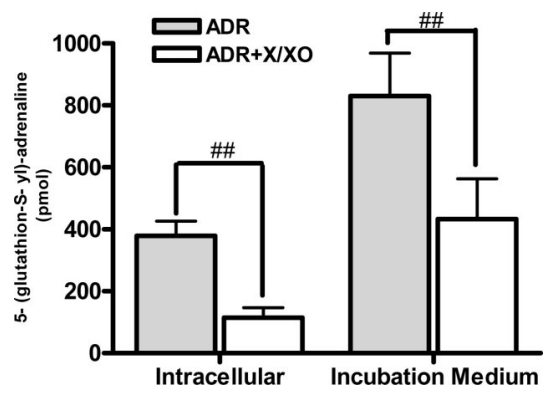

Figure 4. Levels of 5-(glutathion-S-yl)adrenaline formed within the myocytes and incubation medium of cardiomyocyte suspensions incubated with $0.5 \mathrm{mM}$ ADR and $0.5 \mathrm{mM}$ ADR with X/XO. Statistical comparisons, at $3 \mathrm{~h}$, were made using the Mann-Whitney Ram Sum test: ${ }^{\# \#} p<0.01$ for ADR vs ADR and X/XO groups.

In the incubation medium, the same trend was also found, since higher values of adduct were measured in the ADR group $(830 \pm 139 \mathrm{pmol} / \mathrm{mL})$, which represents around twice the levels observed in the group with ADR and X/XO (433 $\pm 130 \mathrm{pmol} /$ $\mathrm{mL}$ ) (Figure 4).

Of note, the presence of the referred adduct with lower concentrations of adrenaline was also evaluated, after a $3 \mathrm{~h}$ incubation of the cardiomyocyte suspensions. In both groups, the lowest concentration of adrenaline that enabled the detection of adduct in the cardiomyocytes was $25 \mu \mathrm{M}$.

Adrenaline Treatment Did Not Induce Changes in Lipid Peroxidation, Protein Carbonylation, Activity of Antioxidant Enzymes, or ATP Concentration. Incubation of cardiomyocyte suspensions for $3 \mathrm{~h}$ with ADR, ADR and X/XO, or just $\mathrm{X} / \mathrm{XO}$ did not induce significant changes in cellular viability or ATP content (data not shown). No differences were found for lipid peroxidation and protein carbonylation.

The activity of three antioxidant enzymes, GR, seleniumdependent GPx, and GST, was evaluated for all the treatments after incubation for $3 \mathrm{~h}$ with no significant differences being observed (data not shown).

\section{Discussion}

The findings of this work showed the ability of adrenaline to undergo a complex oxidation process, which is influenced by the presence of ROS. This oxidation process affects cardiomyocyte homeostasis, contributing to adrenaline-induced cardiotoxic effects. New insights concerning the toxicity of adrenaline can be drawn from this study: (1) reactive oxidative products of adrenaline were formed, specifically, adrenochrome; (2) adrenaline exposure decreased the GSH levels in cardiomyocytes; (3) the reactivity of adrenaline oxidation products enabled the formation of quinoproteins and of a GSH-adrenaline adduct, this last, for the first time detected in cells; and (4) the stability of the intermediary quinone was intimately related to the formation of the reactive products mentioned before and to the microenvironment where the oxidation occurs.

Plasma levels of adrenaline in healthy volunteers at rest are as low as $30 \mathrm{pM}$, while the level of noradrenaline reaches 1 $\mathrm{nM}(8,50)$. However, any alteration in the metabolism of catecholamines or disruption of their transport mechanisms might lead to anomalously high concentrations of these substances (5). The concentrations of adrenaline in plasma greatly increase as a result of adrenal stimuli (8). Namely, in pheochromocytoma patients, plasma concentrations of adrenaline were shown to range from 0.3 to $3.6 \mu \mathrm{M}$, while noradrenaline concentrations can reach $50 \mu \mathrm{M}(1.5-50 \mu \mathrm{M})(7)$.

Moreover, extra-adrenal adrenaline synthesis and phenylethanolamine $N$-methyltransferase have been reported in the 


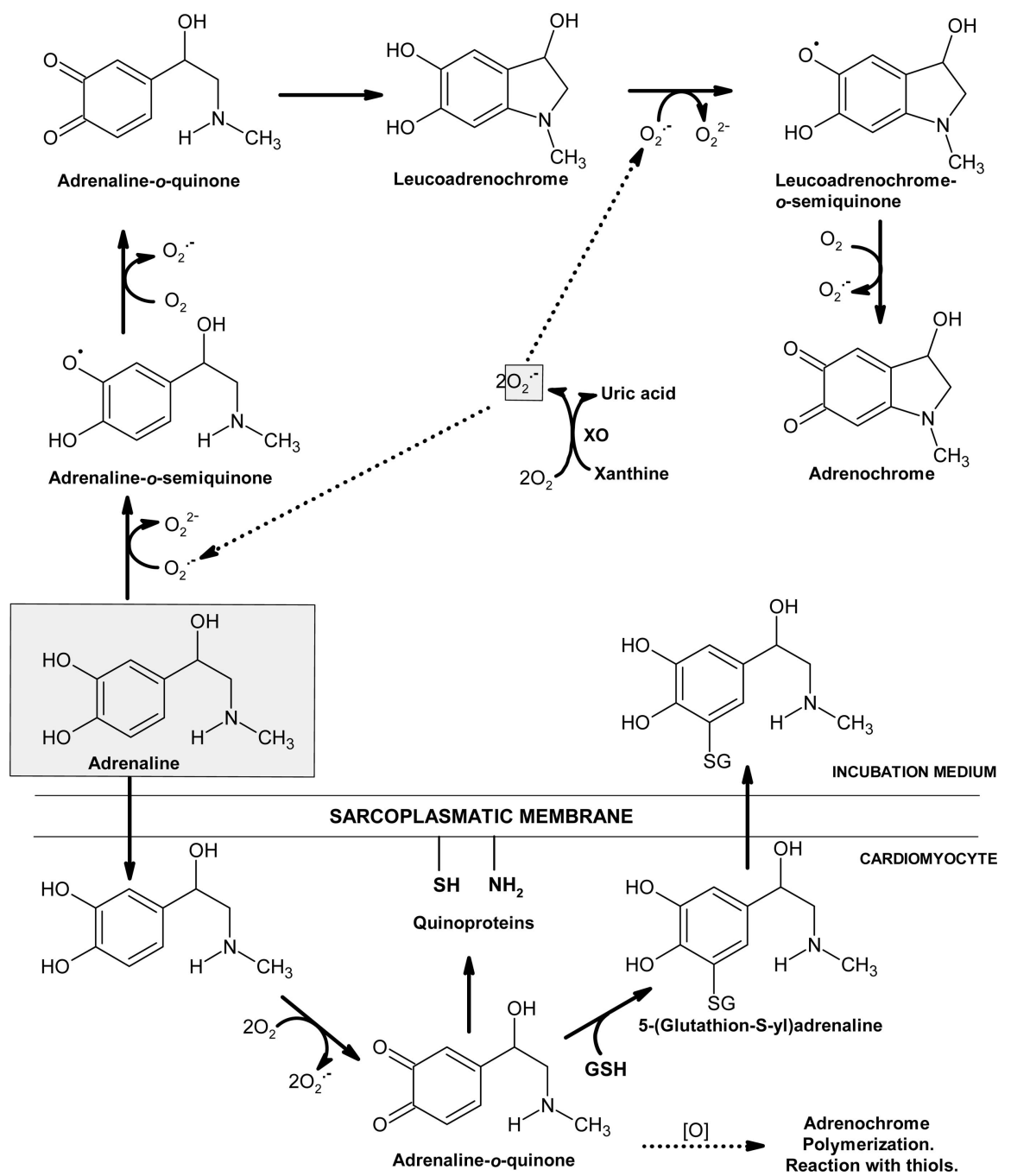

Figure 5. Postulated pathway for the oxidation of adrenaline in cardiomyocytes and incubation medium (not all intermediates are shown, for simplification). The oxidation process of adrenaline initially involves its conversion to $o$-quinone with an $o$-semiquinone intermediary in cardiomyocytes. The $o$-quinone can react with GSH, to form the corresponding GSH conjugate, or react with other nucleophilic groups in the cells. Thus, the higher stability of $o$-quinone where only adrenaline is present favors the formation of the GSH adduct and quinoproteins. The GSH adduct seems to be transported out of the cells. Meanwhile, the $o$-quinone can undergo an irreversible 1,4-intramolecular cyclization, forming leucoadrenochrome. The oxidation to adrenochrome of the unstable leucoadrenochrome is rapid, especially in the group where a ROS generating system $\left(\mathrm{O}_{2}{ }^{\cdot-}\right)$ is present. The formation of adrenochrome is a reaction in which a total of two electrons are removed and adrenochrome semiquinone is the intermediate. Adrenochrome formed in the cells can also suffer conjugation with cellular GSH, leading to its depletion, or polymerize into several other compounds.

heart, and an extensive uptake of adrenaline from the plasma occurs in some pathologic conditions (8). Concentrations are expected to be higher in the heart tissue than the ones reported in the plasma, where the rate of clearance is higher.

In particular, it has been shown that, during heart ischemia, the release of catecholamines becomes non-exocytotoxic and is thought to involve the uptake of carrier-mediated efflux in reverse of its normal transport direction (5), largely increasing the concentration of those biogenic amines in the interstitial space, where they can reach values of $4.7 \mathrm{nM}$ (5). Furthermore, sympathetic neurons can take up adrenaline from circulation and release it upon stimulation in the heart (5). When the enzymes responsible for their catabolism (monoamino oxidase and catechol-o-methyltransferase) are unable to cope efficiently, the catecholamine levels in the heart rise and the catecholamine can undergo oxidation, which is catalyzed by trace metals and several enzymes $(19,21,22)$. The oxidation pathway of adrenaline involves multiple steps (Figure 5). Adrenaline may be converted to an unstable $o$-semiquinone that, after deprotonation and loss of a second electron, gives rise to the corresponding $o$-quinone. At physiological $\mathrm{pH}$, partial deprotonation of the amine group of the side chain of adrenaline leads to an irreversible 1,4-intramolecular cyclization, a reaction that occurs through nucleophilic attack of the nitrogen atom at the 6 position of the quinone ring, to give leucoadrenochrome, which is then further oxidized to adrenochrome $(19,51)$. In vivo, this oxidation pathway may be more complex, since other factors, such as metal ions or other nucleophilic groups, can be involved (24).

Oxidative stress is a condition in which pro-oxidant metabolites exert toxic effects due to their enhanced production and/ or an exhaustion in cellular protection mechanisms (52). There is a growing body of evidence which shows that prolonged ischemia reduces the defense mechanisms within the heart against free radicals (53). Meanwhile, during reperfusion, ROS can be formed above the neutralizing capability of the cells, playing a major role in the pathogenesis of post-ischemic reperfusion injury (11).

Since ROS are formed in I/R phenomena in vivo, an $\mathrm{O}_{2}{ }^{--}$generating system can be used to mimic an oxidative stress condition $(24,54)$. In our work, X/XO was applied to freshly isolated cardiomyocytes, since it is a system suitable for generating ROS. This system was used to mimic the in vivo 
situation, as there are several works reporting an important role of $\mathrm{XO}$ in the pathogenesis of I/R phenomena and other diseases of the heart $(55,56)$. In cultured cardiomyocytes, Durot et al. (54) used X/XO concentrations $0.1 \mathrm{mM}$ per $0.01 \mathrm{unit} / \mathrm{mL}$ reported to be found under pathophysiological conditions. At those concentrations, $\mathrm{X} / \mathrm{XO}$ produced $\mathrm{O}_{2}{ }^{--}$for $10 \mathrm{~min}$ and also small amounts of ${ }^{\bullet} \mathrm{OH}$ radical. The GSH levels are not greatly affected in our work by the presence of the X/XO system, since thiols react slowly with $\mathrm{O}_{2}{ }^{--}$, as previously reported in the nervous system (24).

The functional consequences of the exposure to ROS largely depend of the species that are present (54). Catecholamines react amazingly fast with $\mathrm{O}_{2}{ }^{--}$(23). The burst of ROS caused by $\mathrm{X} / \mathrm{XO}$ determines formation of adrenaline oxidation products, resulting in the formation of semiquinone radicals, $o$-quinones, and later adrenochrome (51) (Figure 5). Moreover, $\mathrm{O}_{2}{ }^{--}$seems to catalyze the conversion of adrenaline to adrenochrome by acting as a propagating species in a cascade reaction during the univalent oxidation of the catecholamine (57). Our results show that adrenaline depletion was more enhanced in the group ADR with $\mathrm{X} / \mathrm{XO}$ both in the cardiomyocytes and in the incubation medium (Figure 1A). In the incubation medium, the decrease in adrenaline levels was accompanied by the evident increase in adrenochrome concentration (Figure 1B), this effect being more pronounced in cells incubated with ADR and X/XO. As observed in a previous work (51), when adrenochrome is generated and adrenaline still exists in solution, adrenochrome seems to accelerate the oxidation of the remaining adrenaline. The formation of adrenochrome has been reported in cardiac diseases, such as those accompanied by leukocytic infiltration (58), myocardial infarction, and cardiomyopathy (3). Unexpectedly, we could not find adrenochrome in the cardiomyocytes. The high reactivity of adrenochrome toward various cellular nucleophiles, such as GSH or proteins $(28,59)$, of the cardiomyocytes may explain its rapid disappearance and also the lower values for GSH observed in cells with ADR and X/XO. Previous results in isolated heart seem to corroborate this binding ability, since when heart is reperfused with radioactive adrenochrome, approximately $50 \%$ of adrenochrome radioactivity remains in the organ, indicating an irreversible binding to the tissues (19). In addition, adrenochrome can undergo further structural modifications throughout the oxidative pathway or rearrange to other substances, forming adrenolutin or polymers (19).

Notwithstanding its toxicity, adrenochrome is reported to inhibit lipid peroxidation (19). A reduced form of adrenochrome (leucoadrenochrome or the corresponding semiquinone) can also act as a particularly efficient antioxidant (19). Thus, it is not surprising that no differences between groups were found in lipid peroxidation. Also, X/XO does not seem to be responsible for any kind of lipid peroxidation (54). The same perspective can justify the observed absence in our work of significant differences in protein carbonylation. The oxidation products of adrenaline are thought to directly react with the nucleophilic compounds and remain bound.

The oxidation of adrenaline will form products other than adrenochrome (Figure 5) $(19,28)$. It seems, in the model adopted in this work, that the amount and nature of adrenaline oxidation products formed were related to the stability of the intermediary quinone (Figure 5). Thus, a less oxidizing medium favored the existence of quinones and their products, while in an oxidizing medium (created by X/XO), the formation of adrenochrome is favored, since the oxidative pathway of leucoadrenochrome is faster (60).
The work of Miyazaki et al. (25) using tyrosinase null mice strengthens our hypothesis. Tyrosinase present in wild mice induces rapid oxidation of dopamine to form stable melanin, with dopamine quinone as an intermediate. In contrast, in tyrosinase null mice, the values for quinoproteins are higher, since, in these animals, quinones are more stable (25).

In our work, levels of quinoproteins in ADR cells are superior to those treated with ADR and X/XO (Figure 1C). These results suggest that the stability of the quinone intermediate is higher in the absence of ROS, allowing the quinone to further react with cellular groups, while in the presence of ROS, adrenaline is rapidly converted into more oxidized species, namely, adrenochrome and its metabolites. Quinones, by themselves, are reported to induce cytotoxicity, immunotoxicity, and carcinogenesis in vivo $(61,62)$. The mechanisms of toxicity are diverse, depending on their chemical structure and the cellular environment in which they are formed. In addition, alkylation of cellular nucleophiles (GSH, proteins, and DNA) by these species may occur to a significant extent, forming covalent adducts that can significantly compromise cellular integrity and function $(25,38$, 61). Thus, the reactivity of adrenaline toward glutathione was evaluated. We observed a time-dependent decline in the level of GSH in cells exposed to ADR, which was potentiated in cells treated with ADR and X/XO (Figure 2). In both groups, the decrease in GSH levels was not accompanied by changes in the activities of the enzymes involved in GSH metabolism or in the GSSG levels, leading to the hypothesis of the occurrence of GSH conjugation with electrophilic compounds. The depletion of intracellular GSH as a result of the catecholamine oxidation process has been previously described $(28,36,40)$, and it increases the cellular vulnerability to further oxidative injury. This fact can be of relevance during cardiopathologic events in humans, since GSH is the major nonproteic antioxidant present in the cells and reacts with several electrophilic compounds.

Although adducts of GSH and dopamine or catechol metabolites of MDMA have already been described (24, 41), until now no GSH-adrenaline adducts had been reported in cells. The rate of cyclization of adrenaline $o$-quinone was probably considered to be too fast for that to occur (27). We report, for the first time, the detection of 5-(glutathion-S-yl)adrenaline in cardiomyocytes, even for adrenaline concentrations as low as $25 \mu \mathrm{M}$.

The $o$-quinone formed during the adrenaline oxidation process (51), in the presence of GSH, may conjugate to form glutathionyl adducts (63) (Figure 5). The catechol thioether formed by the addition of the sulfur atom to the quinone ring (62) may be much more redox active than an unsubstituted quinone $(34,62,64)$. This capacity to further oxidize may improve their ability to undergo a redox cycle (62), which contributes to the cytotoxicity of these adducts $(24,29,61,64)$. GSH conjugates were found to covalently bind with DNA, raising the question of their ability to cause carcinogenicity $(62,64)$. They were also reported as nephrotoxic $(30,62)$ and neurotoxic $(24,31,62)$ compounds.

The measurement of these compounds (adduct of glutathione and quinoproteins) is an index of oxidation of the parent catechol, but also a direct measurement of nucleophilic modification. The selective increase in the levels of the GSHadrenaline adduct and quinoproteins in the groups exposed to ADR suggest that these reactions are favored where quinone is more stable $(19,25)$. This was the case for the levels of the GSH adduct in the cells, but also in the incubation medium. The high values of 5-(glutathion- $S$-yl)adrenaline in the incuba- 
tion medium of both groups exposed to adrenaline may suggest a possible mechanism of GSH conjugate efflux in cardiomyocytes (65).

In conclusion, our study has provided several lines of evidence suggesting that an increased rate of adrenaline oxidation is associated with cardiotoxicity and that the adrenaline oxidation pathway depends greatly on the surrounding medium. The catecholamine oxidation products are able to form covalent bounds with the cellular nucleophilic groups (belonging to either GSH or macromolecules). Adrenaline-induced modifications to the protein structure may result in alteration of the cellular function, although decreases in ATP levels or increases in the rate of cell death were not observed in this work. The findings of our work may prove to be important in clarifying adrenalineinduced toxicity but also in highlighting its oxidation pathway in a cellular medium and the influence of the microenvironment where it occurs.

Acknowledgment. This work received financial support from "Fundação para a Ciência e Tecnologia" (FCT) and "Programa Operacional Ciência e Inovação 2010”, Portugal (POCI-2010), through FEDER European Community cofunding (Project POCI/SAU-OBS/55849/2004). V.M.C. acknowledges FCT for her Ph.D. grant (SFRD/BD/17677/ 2004).

\section{References}

(1) World Health Organization (2003) The World Health Report 2003 : Shaping the Future, in WHO World Health Organization Press 2003.

(2) Lefer, D. J., and Granger, N. (2000) Oxidative stress and cardiac disease. Am. J. Med. 109, 315-323.

(3) Behonick, G. S., Novak, M. J., Nealley, E. W., and Baskin, S. I. (2001) Toxicology update: The cardiotoxicity of the oxidative stress metabolites of catecholamines (aminochromes). J. Appl. Toxicol. 21 (Suppl. 1), S15-S22.

(4) Esler, M., and Kaye, D. (2000) Measurement of sympathetic nervous system activity in heart failure: The role of norepinephrine kinetics. Heart Failure Rev. 5, 17-25.

(5) Lameris, T. W., Zeeuw, S., Alberts, G., Boomsma, F., Duncker, D. J., Verdouw, P. D., Man in't Veld, A. J., and van den Meiracker, A. H. (2000) Time course and mechanism of myocardial catecholamine release during trasient ischemia in vivo. Circulation 101, 2645-2650.

(6) Kjaer, M. (1998) Adrenal medulla and exercise training. Eur. J. Appl. Physiol. Occup. Physiol. 77, 195-199.

(7) Gerlo, E., and Sevens, C. (1994) Urinary and plasma catecholamines and urinary catecholamine metabolites in pheochromocytoma: Diagnostic value in 19 cases. Clin. Chem. 40, 250-256.

(8) Goldstein, D. S., Eisenhofer, G., and Kopin, I. J. (2003) Sources and significance of plasma levels of catechols and their metabolites in humans. J. Pharmacol. Exp. Ther. 305, 800-811.

(9) Broadley, K. J., and Penson, P. E. (2004) The roles of $\alpha$ - and $\beta$-adrenoceptor stimulation in myocardial ischaemia. Auton. Autacoid Pharmacol. 24, 87-93.

(10) Zhong, J.-q., and Dorian, P. (2005) Epinephrine and vasopressin during cardiopulmonary resuscitation. Resuscitation 66, 263-269.

(11) Flaherty, J. T., and Weisfeldt, M. L. (1988) Reperfusion injury. Free Radical Biol. Med. 5, 409-419.

(12) Ferrari, R., Ceconi, C., Curello, S., Cargnoni, A., De Giuli, F., and Visioli, O. (1992) Occurrence of oxidative stress during myocardial reperfusion. Mol. Cell. Biochem. 111, 61-69.

(13) Flaherty, J. T. (1991) Myocardial injury mediated by oxygen free radical. Am. J. Med. 91, 79S-88S.

(14) Vollaard, N. B., Shearman, J. P., and Cooper, C. (2005) Exerciseinduced oxidative stress: Myths, realities and physiological relevance. Sports Med. 35, 1045-1062.

(15) Elahi, M. M., and Matata, B. M. (2006) Free radicals in blood: Evolving concepts in the mechanism of ischemic heart disease. Arch. Biochem. Biophys. 450, 78-88.

(16) Frangogiannis, N. G., Smith, C. W., and Entman, M. L. (2002) The inflammatory response in myocardial infarction. Cardiovasc. Res. 53, $31-47$.

(17) Halliwell, B. (2006) Oxidative stress and neurodegeneration: Where are we now? J. Neurochem. 97, 1634-1658.

(18) Sarkar, D., and Fisher, P. B. (2006) Molecular mechanisms of agingassociated inflammation. Cancer Lett. 236, 13-23.
(19) Bindoli, A., Rigobello, M. P., and Deeble, D. J. (1992) Biochemical and toxicological properties of the oxidation products of catecholamines. Free Radical Biol. Med. 13, 391-405.

(20) Dhalla, S. N., Sasaki, H., Mochizuki, S., Dhalla, S. K., Liu, X., and Elimban, V. (2001) Catecholamine-induced cardiomyopathy, 3rd ed., Taylor and Francis: London.

(21) Heacock, R. A. (1959) The chemistry of adrenochrome and related compounds. Chem. Rev. 59, 181-237.

(22) Foppoli, C., Coccia, R., Cini, C., and Rosei, M. A. (1997) Catecholamines oxidation by xanthine oxidase. Biochim. Biophys. Acta 1334, 200-206.

(23) Spencer, J. P. E., Jenner, P., and Halliwel, B. (1995) Superoxidedependent depletion of reduced glutathione by L-DOPA and dopamine. NeuroReport 6, 1480-1484.

(24) Spencer, J. P. E., Jenner, P., Daniel, S. E., Lees, A. J., Marsden, D. C., and Halliwell, B. (1998) Conjugates of catecholamines with cysteine and GSH in Parkinson's disease: Possible mechanism of formation involving reactive oxygen species. J. Neurochem. 71, 2112-2122.

(25) Miyazaki, I., Asanuma, M., Diaz-Corrales, F. J., Fukuda, M., Kitaichi, K., Miyoshi, K., and Ogawa, N. (2006) Methamphetamine-induced dopaminergic neurotoxicity is regulated by quinone formation-related molecules. FASEB J. 20, 571-573.

(26) LaVoie, M. J., and Hastings, T. G. (1999) Dopamine Quinone Formation and Protein Modification Associated with the Striatal Neurotoxicity of Methamphetamine: Evidence against a Role for Extracellular Dopamine. J. Neurosci. 19, 1484-1491.

(27) Rupp, H., Dhalla, K., and Dhalla, N. (1994) Mechanisms of cardiac cell damage due to catecholamines: Significance of drugs regulating central sympathetic outflow. J. Cardiovasc. Pharmacol. 24, S16-S24.

(28) Bindoli, A., Rigobello, M. P., and Galzigna, S. A. (1989) Toxicity of aminochromes. Toxicol. Lett. 48, 3-20.

(29) Spencer, J. P. E., Whiteman, M., Jenner, P., and Halliwel, B. (2002) 5-S-Cysteinyl-conjugates of catecholamines induce cell damage, extensive DNA base modication and increases in caspase-3 activity in neurons. J. Neurochem. 81, 122-129.

(30) Carvalho, M., Hawksworth, G., Milhazes, N., Borges, F., Monks, T. J., Fernandes, E., Carvalho, F., and Bastos, M. L. (2002) Role of metabolites in MDMA (ecstasy)-induced nephrotoxicity: An in vitro study using rat and human renal proximal tubular cells. Arch. Toxicol. 76, 581-588.

(31) Capela, J. P., Meisel, A., Abreu, A. R., Branco, P. S., Ferreira, L. M., Lobo, A. M., Remião, F., Bastos, M. L., and Carvalho, F. (2006) Neurotoxicity of Ecstasy Metabolites in Rat Cortical Neurons and Influence of Hyperthermia. J. Pharmacol. Exp. Ther. 316, 53-61.

(32) Haworth, R. A. (1990) Use of Isolated Adult Myocytes to Evaluate Cardiotoxicity. II. Preparation and Properties. Toxicol. Pathol. 18, 521530.

(33) Farmer, B. B., Harris, R. A., Jolly, W. W., Hathaway, D. R., Katzberg, A., Watanabe, A. M., Whitlow, A. L., and Besch, H. R., Jr (1977) Isolation and Characterization of Adult Rat Heart Cells. Arch. Biochem. Biophys. 179, 545-558.

(34) Macedo, C., Branco, P. S., Ferreira, L. M., Lobo, A., Capela, J. P., Fernandes, E., Bastos, M. L., and Carvalho, F. (2007) Synthesis and Cyclic Voltammetry Studies of 3,4-Methylenedioxymethamphetamine (MDMA) Main Human Metabolites. J. Health Sci. 53, 31-42.

(35) Remião, F., Carmo, H., Carvalho, F., and Bastos, M. L. (2001) Cardiotoxicity studies using freshly isolated calcium-tolerant cardiomyocytes from adult rat. In Vitro Cell. Dev. Biol.: Anim. 37, 1-4.

(36) Remião, F., Carvalho, M., Carmo, H., Carvalho, F., and Bastos, M. L. (2002) $\mathrm{Cu}^{2+}$-induced isoproterenol oxidation into isoprenochrome in adult rat calcium-tolerant cardiomyocytes. Chem. Res. Toxicol. 15, 861-869.

(37) Cordeiro, J. M., Howlett, S. E., and Ferrier, G. R. (1994) Simulated ischaemia and reperfusion in isolated guinea pig ventricular myocytes. Cardiovasc. Res. 28, 1794-1802.

(38) Remião, F., Rettori, D., Han, D., Carvalho, F., Bastos, M. L., and Cadenas, E. (2004) Leucoisoprenochrome-o-semiquinone formation in freshly isolated adult rat cardiomyocytes. Chem. Res. Toxicol. 17, $1584-1590$.

(39) Carvalho, M., Remião, F., Milhazes, N., Borges, F., Fernandes, E., Monteiro, M. C., Gonçalves, M. J., Seabra, V., Amado, F., Carvalho, F., and Bastos, M. L. (2004) Metabolism Is Required for the Expression of Ecstasy-Induced Cardiotoxicity in Vitro. Chem. Res. Toxicol. 17, 623-632.

(40) Remião, F., Carmo, H., Carvalho, F., and Bastos, M. L. (2001) Copper enhances isoproterenol toxicity in isolated rat cardiomyocytes. Cardiovasc. Toxicol. 1, 195-204.

(41) Carvalho, M., Milhazes, N., Remião, F., Borges, F., Fernandes, E., Amado, F., Monks, T. J., Carvalho, F., and Bastos, M. L. (2004) Hepatotoxicity of 3,4-methylenedioxyamphetamine and $\alpha$-methyldopamine in isolated rat hepatocytes: Formation of glutathione conjugates. Arch. Toxicol. 78, 16-24. 
(42) Carvalho, F., Fernandes, E., Remião, F., and Bastos, M. L. (1999) Effect of d-amphetamine repeated administration on rat antioxidant defences. Arch. Toxicol. 73, 83-89.

(43) De Luca, M., and McElroy, W. D. (1974) Kinetics of the firefly luciferase catalyzed reactions. Biochemistry 13, 921-925.

(44) Levine, R. L., Garland, D., Oliver, C. N., Amici, A., Climent, I., Lenz, A., Ahn, B., Dhaltiel, S., and Stadtman, E. R. (1990) Determination of carbonyl content in oxidatively modified proteins. Methods Enzymol. 186, 464-478.

(45) Lowry, O. H., Rosebrough, N. J., Farr, A. L., and Randall, R. J. (1951) Protein measurement with the Folin phenol reagent. J. Biol. Chem. 193, 265-275.

(46) Bradford, M. M. (1976) A rapid and sensitive method for the quantitation of microgram quantities of protein utilizing the principle of protein dye binding. Anal. Biochem. 72, 248-254.

(47) Paz, M. A., Fluckiger, R., Boak, A., Kagan, H. M., and Gallop, P. M. (1991) Specific Detection of Quinoproteins by Redox-cycling Staining. J. Biol. Chem. 2, 689-692.

(48) Silva, R., Boldt, S., Costa, V. M., Carmo, H., Carvalho, M., Carvalho, F., Bastos, M. L., Lemos-Amado, F., and Remião, F. (2007) Evaluation of GSH adducts of adrenaline in biological samples. Biomed. Chromatogr. 21, 670-679.

(49) Dickinson, D. A., and Forman, H. J. (2002) Glutathione in defense and signaling: Lessons from a small thiol. Ann. N.Y. Acad. Sci. 973, 488-504.

(50) Wheatley, A. M., Thandroyen, F. T., and Opie, L. H. (1985) Catecholamine-induced myocardial cell damage: Catecholamines or adrenochrome. J. Mol. Cell. Cardiol. 17, 349-359.

(51) Bindoli, A., Scutari, G., and Rigobello, M. P. (1999) The role of adrenochrome in stimulating the oxidation of catecholamines. $\mathrm{Neu}$ rotox. Res. 1, 71-80.

(52) Ferrari, R., Agnoletti, L., Comini, L., Gaia, G., Bachetti, T., Cargnoni, A., Ceconi, C., Curello, S., and Visioli, O. (1998) Oxidative stress during myocardial ischaemia and heart failure. Eur. Heart J. 19, B2B11.

(53) Ferrari, R., Ceconi, C., Curello, S., Alfieri, O., and Visioli, O. (1993) Myocardial damage during ischaemia and reperfusion. Eur. Heart J. 14, 25-30.

(54) Durot, I., Maupoil, V., Ponsard, B., Cordelet, C., Vergeley-Vandriesse, C., Rochette, L., and Athias, L. (2000) Oxidative injury of isolated cardiomyocytes: Dependence on free radical species. Free Radical Biol. Med. 29, 846-857.

(55) Baldus, S., Müllerleile, K., Chumley, P., Steven, D., Rudolph, V., Lund, G. K., Staude, H.-J., Stork, A., Köster, R., Kähler, J., Weiss, C., Münzel, T., Meinertz, T., Freeman, B. A., and Heitzer, T. (2006) Inhibition of xanthine oxidase improves myocardial contractility in patients with ischemic cardiomyopathy. Free Radical Biol. Med. 41, 1282-1288.

(56) Chambers, D. E., Parks, D. A., Patterson, G., Roy, R., McCord, J. M., Yoshida, S., Parmley, L. F., and Downey, J. M. (1985) Xanthine oxidase as a source of free radical damage in myocardial ischemia. $J$. Mol. Cell. Cardiol. 17, 145-152.

(57) Mishra, H. P., and Fridovich, I. (1972) The role of superoxide anion in the autoxidation of epinephrine and a single assay for superoxide dismutase. J. Biol. Chem. 247, 3170-3175.

(58) Matthews, S. B., Henderson, A. H., and Campbell, A. K. (1985) The adrenochrome pathway: The major route for adrenalin catabolism by polymorphonuclear leucocytes. J. Mol. Cell. Cardiol. 17, 339-348.

(59) Bindoli, A., Deeble, D. J., Rigobello, M. P., and Galzigna, L. (1990) Direct and respiratory chain-mediated redox cycling of adrenochrome. Biochim. Biophys. Acta 1016, 349-356.

(60) Hawley, M. D., Tatawawadi, S. V., Piekarski, R., and Adams, R. N. (1967) Electrochemical studies of the oxidation pathways of catecholamines. J. Am. Chem. Soc. 89, 447-450.

(61) Bolton, J. L., Trush, M. A., Penning, T. M., Dryhurst, G., and Monks, T. J. (2000) Role of quinones in toxicology. Chem. Res. Toxicol. 13, $135-160$.

(62) Monks, T. J., and Lau, S. S. (1992) Toxicology of quinone-thioethers. Crit. Rev. Toxicol. 22, 243-270.

(63) Monks, T. J., Jones, D. C., Bai, F., and Lau, S. S. (2004) The role of metabolism in 3,4-( \pm -methylenedioxyamphetamine and 3,4-( $( \pm)$ methylenedioxymethamamphetamine (Ecstasy) toxicity. Ther. Drug Monit. 26, 132-136.

(64) Monks, T. J., and Lau, S. S. (1997) Biological reactivity of polyphenolic-glutathione conjugates. Chem. Res. Toxicol. 10, 1296-1313.

(65) Ghosh, S., Ting, S., Lau, H., Pulinilkunnil, T., An, D., Qi, D., Abrahani, M. A., and Rodrigues, B. (2004) Increased efflux of glutathione conjugate in acutely diabetic cardiomyocytes. Can. J. Physiol. Pharmacol. 82, 879-887.

\section{TX7000916}

